\title{
A tradução do pensamento de Angela Davis para o Brasil: por uma história das origens interseccionais do feminismo*
}

Clarisse Goulart Paradis**

Angela Davis é umas das mais importantes feministas contemporâneas. Sua potente história de luta política encarnou uma geração de reivindicações por humanidade, igualdade $e$ liberdade não só para o povo negro, mas para todas as parcelas oprimidas da sociedade. O sentido de suas reflexões aliaram, como ninguém, teoria e prática, em uma leitura da história, da sociedade $e$ da política, que estiveram e ainda estão fundamentalmente conectadas com um novo devir, uma transformação profunda da realidade e, portanto, seu pensamento entra no rol das teorias críticas, do pensamento produzido desde a subalternidade e de profundo valor para um outro mundo possível.

Em 2016, a obra "Mulheres, raça e classe", escrita por Davis em 1981, ganhou uma edição brasileira, lançada pela Editora Boitempo. Ainda que nesse espaço de trinta e cinco anos, feministas brasileiras se esforçaram para se apropriar dessa e de outras obras de Davis, organizando estudos e traduções livres, o lançamento da obra no Brasil, nesse momento, tem um significado importante. De fato, o reencontro das brasileiras e brasileiros com

* Recebida em 13 de janeiro de 2017, aceita em 21 de novembro de 2018. Resenha de: DAVIS, Angela. Mulheres, raça e classe. São Paulo, Boitempo, 2016.

** Professora da Universidade de Integração Internacional de Lusofonia Afrobrasileira (UNILAB/Campus dos Malês) e pesquisadora do grupo de pesquisa "Pós-colonialidade, feminismos e epistemologias anti-hegemônicas" (FEMPOS/UNILAB Malês), São Francisco do Conde, BA, Brasil. clarisseparadis@unilab.edu.br/https://orcid.org/0000-0002-5767-2479 
Davis é requerido, mais do que nunca, em um momento que, de um lado, exige novas reflexões e apropriações críticas para enfrentamento do recrudescimento das forças conservadoras e seu sentido privatista, racista e patriarcal e, de outro lado, acompanha um processo importante de fortalecimento da luta feminista $e$, especialmente, da revalorização e mobilização das leituras $e$ práticas das mulheres negras para o feminismo.

O livro está dividido em doze capítulos, que cobrem desde uma das mais terríveis experiências de desumanização, violência $e$ expropriação do corpo $e$ vida que foi a escravidão, no século XIX nos Estados Unidos, até os imensos desafios vivenciados pela população negra, especialmente as mulheres, no pós-abolição. A análise de Davis sobre o papel social das mulheres negras na sociedade colonial escravocrata estadunidense partiu da inconsistência dos estudos historiográficos anteriores. Para a autora, as mulheres negras escravizadas, como também nos mostra bell hooks (1982) se encarregaram dos trabalhos pesados, na lavoura e na mineração, junto aos homens, porém sofriam uma forma própria de terrorismo e tortura, que era o estupro sistemático.

Uma vez proibido o tráfico, no início do século, as mulheres passaram a ser obrigadas a reproduzir mão de obra. Muitas não tinham o direito a criar seus filhos, que logo eram separados de suas mães. Ao localizar o papel social das mulheres na escravidão, Davis buscou demonstrar que as mulheres negras eram vistas como anomalias quanto ao padrão de feminilidade do século XIX, afinal assumiam em pé de igualdade o trabalho produtivo $e$ não eram consideradas mães.

É preciso lembrar que nesse período, a divisão da esfera da produção e reprodução, tem seu auge no período de expansão do capitalismo industrial, consagrando essa divisão também como sexual. Essa transformação acompanha uma revalorização da produção, eliminando o reconhecimento da importância das tarefas que não tivessem valor no mercado. É a partir desse processo que vai sendo forjada a figura da dona de casa - modelo universal de feminilidade e ideal de prosperidade da classe média 
(Davis, 2016). Poucas mulheres, obviamente, poderiam ser representadas pelo ideal da feminilidade universal, no entanto, parte constitutiva do modo como seriam reconhecidas $e$ oprimidas, tinha a ver com o desajuste vis-à-vis esse ideal.

De acordo com a autora, a consciência das mulheres negras sobre a opressão a qual estavam submetidas sob esse ideal de feminilidade pode ser simbolizado pelo discurso de Sojourner Truth, "Ain't I women", proferido durante uma convenção de mulheres em Akron, Ohio, em 1851 (Davis, 2016). Truth nasceu em 1797, foi escravizada e conseguiu liberdade em 1826. Em 1843 se mudou para Nova York e decidiu militar contra as injustiças. Se tornou uma liderança religiosa e política, figura importante do movimento abolicionista e era reconhecida por sua habilidade como oradora, em um momento em que poucas mulheres ousavam falar em público. Além da luta pela abolição, Sojourner também lutou pelo direito de voto para as mulheres.

No discurso, Truth expressou a indignação com a afirmação de um dos homens na convenção, que havia zombado da luta pelo direito ao voto, já que, na sua concepção, as mulheres não poderiam fazer nada sem ajuda masculina (Davis, 2016). Como afirma Davis, Truth enterrou o argumento do "sexo frágil" $e$ também buscou defender a ideia de que a sua experiência como mulher negra e antes escravizada era também retrato do conjunto das mulheres e que suas reivindicações eram tão válidas quanto a das mulheres brancas. Segue trecho do discurso:

Aqueles homens ali dizem que as mulheres precisam de ajuda para subir em carruagens, e devem ser carregadas para atravessar valas, e que merecem o melhor lugar onde quer que estejam. Ninguém jamais me ajudou a subir em carruagens, ou a saltar sobre poças de lama, e nunca me ofereceram melhor lugar algum! E não sou uma mulher? Olhem para mim? Olhem para meus braços! Eu arei $e$ plantei, e juntei a colheita nos celeiros, e homem algum poderia estar à minha frente. E não sou uma mulher? Eu poderia trabalhar tanto e comer tanto quanto qualquer homem - desde que eu tivesse oportunidade para isso - $e$ 
suportar o açoite também! E não sou uma mulher? Eu pari treze filhos e vi a maioria deles ser vendida para a escravidão, e quando eu clamei com a minha dor de mãe, ninguém a não ser Jesus me ouviu! E não sou uma mulher? (Truth, 2014).

Davis também examinou a inclusão das mulheres e a reivindicação pela igualdade de gênero na luta abolicionista. Sua narrativa buscou visibilizar atores $e$ atrizes chaves, momentos cruciais em que essa luta foi ganhando terreno e também as contradições entre a luta por direitos e as intersecções entre raça, classe e gênero. Quatro pontos são discutidos pela autora: o primeiro refere-se à participação das mulheres brancas no movimento abolicionista. Este atraiu um número muito significativo de mulheres tanto da classe média, quanto operárias, que compreenderam o vocabulário de luta contra escravidão como significativo para se opor à opressão no casamento e no mundo do trabalho.

Um segundo ponto salientado refere-se ao modo como o movimento abolicionista incorporou a reivindicação pela igualdade de gênero, especialmente o direito ao voto feminino. Enquanto em alguns momentos do movimento e por alguns atores, essa reivindicação foi menosprezada ou negada, lideranças importantes como o militante negro Frederick Douglass declarava publicamente seu apoio, além de serem identificadas referências importantes na impressa negra e em eventos que congregaram abolicionistas negros/as.

Um terceiro ponto refere-se ao papel das mulheres negras, que também lutaram incessantemente pela causa abolicionista e também contra a opressão das mulheres. Nos Estados Unidos, assim como no Brasil, no período escravocrata, elas desenvolveram papel importante na orquestração de fugas $e$ criação de comunidades livres. A autora também destacou momentos importantes de solidariedade entre as mulheres brancas e negras, mesmo no contexto do fosso social que as separavam, especialmente pela atuação das irmãs Grimké e pelas iniciativas 
de algumas professoras na luta pela alfabetização da população negra (Davis, 2016).

O quarto ponto explorado por Davis refere-se aos desencontros entre uma importante ala do movimento sufragista $e$ o abolicionista. Ainda que as principais lideranças do recémnascido movimento feminista americano tenham sido forjadas no âmbito da luta antiescravista, sua oposição à conquista do voto pelos homens negros, este entendido como ameaça à conquista do voto das mulheres, demonstrou inconsistências e lacunas na sua consciência de classe e também explicitou o quanto elas possuíam ainda traços racistas em suas argumentações, $e$, portanto, não conseguiram perceber a conexão entre "escravidão, exploração econômica e opressão social das mulheres" (Davis, 2016:75).

O período pós-abolição e, especialmente o final do século XIX e início do século XX é compreendido por Davis como um momento em que o cruzamento entre racismo e sexismo foi ganhando novas fontes de legitimação. As mulheres negras foram sendo incorporadas ao trabalho remunerado, mas nos postos mais precários. O serviço doméstico mantinha-se como "selo da escravidão" (Davis, 2016:98), que convivia com alta precarização $e$ foi renovando as relações de exploração entre brancas de classe média $e$ as mulheres negras.

Também nesse período, a autora reconheceu que o mito do estuprador negro reforçou uma onda dramática de violência, especialmente por parte de grupos de supremacia branca, que praticavam linchamentos contra homens negros. As mulheres negras se organizaram fortemente contra tal atrocidade, construindo campanhas e entidades e projetando importantes lideranças. A luta pelos direitos sexuais e reprodutivos também foi examinada, especialmente pela ascensão do movimento eugenista $e$ das iniciativas de esterilização em massa das mulheres negras $e$ pobres.

É importante reconhecer, por fim, o esforço de Davis de dar voz e rosto às mulheres que lutaram pela emancipação dos/as trabalhdores/as e do povo negro. Muitas foram as personagens 
aguerridas da narrativa da autora, que buscou destacar, inclusive, lideranças importantes dos partidos socialistas e comunistas, negras e brancas, que contribuíram decisivamente para que a organização de trabalhadores e trabalhadoras reconhecesse a centralidade da luta antirracista.

É possível destacar algumas das várias contribuições da obra de Angela Davis para a teoria feminista. Ao demonstrar que as mulheres resistiram à escravidão, a partir de diferentes estratégias $e$ ao visibilizar suas formas de luta, passando pelos movimentos abolicionistas, pela luta por educação e também pela resistência à violência sistemática sofrida pela população negra no pósabolição, Davis reconheceu as mulheres negras como sujeitos sociais e políticos fundamentais para a história da emancipação feminina e do povo negro.

Sua obra contribui para a tarefa ainda indiscutivelmente inacabada de resgatar a história do feminismo como tradição do pensamento político, reconhecendo que o traço interseccional esteve presente desde as suas origens. Ainda que essa trajetória não tenha se dado sem conflitos, a autora demonstra que existiu a preocupação em construir, em diferentes momentos e a partir de diferentes atores e atrizes, estratégias de emancipação que fossem, de fato, completas. Assim, a autora enriqueceu e ampliou a história de luta das mulheres.

A narrativa de Davis nos leva a revisar e aprofundar as caracterizações do que foi convencionado chamar de primeira onda do feminismo. É preciso abarcar nesse primeiro momento de ascensão da luta organizada e massiva das mulheres, não apenas o direito ao voto, mas sem dúvida uma moção pela liberdade, que incluiu a luta contra a terrível experiência da escravidão e suas cicatrizes, a luta contra a violência patriarcal e a luta pelo direito à contribuição ao mundo público, pela atuação política e pela inserção no trabalho remunerado.

A obra de Davis nos mostra, ainda, que a linguagem antirracista foi fundamental para dar base para a luta feminista. É a partir do vocabulário da liberdade que a luta feminista tem a tarefa de construir as bases para igualdade entre todas as 
mulheres, conectando sua história, a luta pela autonomia do corpo, a defesa de seus territórios e o reconhecimento de seu trabalho.

O trabalho de Davis nos inspira a recontar a história da luta das mulheres, a partir de um olhar que inclua o exame das contradições dos contextos políticos, as estratégias perseguidas pelas mulheres organizadas $e$ de modo interseccional, compreendendo historicamente como gênero, raça e classe foram se configurando para manutenção das opressões e para as possibilidades de emancipação. Nos resta a tarefa de resgatar as vozes que historicamente se tornaram invisíveis, mas que contribuíram decisivamente para o feminismo latino-americano. Trabalhadoras, mulheres do campo e das cidades, operárias, indígenas, mulheres afrolatinas e caribenhas, que, como suas irmãs negras estadunidenses, produziram, na sua prática, uma pedagogia da libertação.

\section{Referências bibliográficas}

DAVIS, Angela. Mulheres, raça e classe. São Paulo, Boitempo, 2016 (1981).

HOOKS, bell. Ain't I a woman: black women and feminism. London, Pluto Press, 1982.

TRUTH, Soujourner. E não sou uma mulher? 2014 [http://www.geledes.org.br/e-nao-sou-uma-mulher-sojournertruth/\#gs.h8jBXJA - acesso em 23 nov. 2016]. 